\title{
Acculturation and overseas assignments: A review and research agenda
}

\author{
Miguel Gonzalez-Loureiro ${ }^{\mathrm{a}, \mathrm{b}}$, Timothy Kiessling ${ }^{\mathrm{c}}$, Marina Dabic ${ }^{\mathrm{d}, \mathrm{e}, *}$ \\ a University of Vigo, Spain \\ b Escola Superior de Tecnologia e Gestão de Felgueiras, Portugal \\ c Bilkent University, Turkey \\ d University of Zagreb, Croatia \\ e Nottingham Trent University, UK
}

\section{A R T I C L E I N F O}

\section{Article history:}

Available online 16 June 2015

\section{Keywords:}

Acculturation

Overseas assignment

Expatriate

Literature review

\begin{abstract}
A B S T R A C T
This review analyzes two streams of literature that are exploring a similar phenomenon from separate perspectives and only recently have they began to overlap; that of migrant acculturation (from the psychology, sociology and anthropology research) and international assignee adjustment (from the international business research stream). We conducted a multiple correspondence analysis on a sample of 389 articles to provide the intellectual structure of the research in these fields.

Our research indicates that: (1) the standard $2 \times 2$ matrix of acculturation is insufficient; (2) most past research focuses on USA to other countries and vice versa, suggesting there is much work left to explore other pairs of cultures ("there and back again" is not the same globally); (3) as global organizations are dominating the marketplace with many various staffing forms, variables such as corporate culture and management interaction will need to be incorporated; (4) research needs to include dynamics over time as many individuals who have worked outside of their home country often become multi-cultural with a global mindset and the typical acculturation framework is insufficient; (5) past acculturation research focuses on the work or the sociocultural context separately, while both need to be included; (6) and the extended family (parents, relatives, close friends, etc.) need to be considered.
\end{abstract}

(c) 2015 Elsevier Ltd. All rights reserved.

\section{Introduction}

Our research attempts to review the appropriateness of extant acculturation frameworks in regard to the differing types of overseas assignments, suggest where acculturation in the 21 st century should focus and to propose a future research agenda to guide more scholarly work in this area. The motivation for our research is that two streams of literature have been exploring this phenomenon from separate perspectives and only recently have they began to overlap; that of acculturation (from the psychology, sociology and anthropology-PSA research) and international assignee adjustment (from the international business-IB research stream) (Lu, Samaratunge, \& Härtel, 2012). Acculturation from the PSA fields focuses on immigrants to a new country and their degree of adaptation (Berry, 1997) while the IB research focuses on the relocation of employees

\footnotetext{
* Corresponding author at: University of Zagreb, Croatia.

E-mail addresses: mloureiro@uvigo.es (M. Gonzalez-Loureiro), kiessling@bilkent.edu.tr (T. Kiessling), mdabic@efzg.hr (M. Dabic).
} 
to a new country and their relative success in the work assignment (Okpara \& Kabongo, 2011). The success of both types of individuals has the focus upon the host country and the ability of the individual to adapt to the new culturally challenging circumstances.

The unit of analysis of the PSA acculturation research was the understanding of the integration and adaptation process upon migration and the subsequent necessity for policy makers in the receiving countries to understand the immigrants' issues (Berry, Phinney, Kwak, \& Sam, 2006). Recent PSA research combined cultural fit research and acculturation research to assist in explaining how an individual's personality traits, values, beliefs and behavior, as well as their adaptation to the host country are affected (Schiefer, Möllering, \& Daniel, 2012). The research suggests that immigrant's success in following the four acculturation strategies (Assimilation, Integration, Marginalization and Separation) (Berry, 1997) will be moderated by the degree of fit between the individual and the society in terms of cultural fit (Juang, Nguyen, \& Lin, 2006).

PSA acculturation suggests that immigrants have to consider two key points: the importance of the preservation of their identity and characteristics pertaining to their home country; and how important is it to participate in the host country (Leong, 2014). The PSA current literature accepts that of the four acculturation strategies, integration (commitment to both home country heritage and adaption to the new host country) will be more successful as there will be lower stress, higher self-esteem, pro-social behaviors, fewer negative anti-social behavior of the adolescent, higher life satisfaction and a more positive workplace well-being (Berry \& Sabatier, 2010; Scottham \& Dias, 2010; Wang, Schwartz, \& Zamboanga, 2010). The PSA acculturation research is beginning to cross-over into research that has been the focus of the IB field; that of examining work related attitudes in regard to the acculturation orientations and work-related well-being (Peeters \& Oerlemans, 2009).

Although the concept of acculturation has been studied scientifically since 1919 (Rudmin, 2003), the standard framework for PSA acculturation research (Assimilation, Integration, Marginalization and Separation) (Berry, 1997) now is being challenged to think beyond this approach (Schwartz, Unger, Zamboanga, \& Szapocznik, 2010). Recent PSA research suggests that perhaps a more selective approach depending upon the type of intercultural contact such as private, public or work environment might be more successful (Navas et al., 2005). For example, Turkish immigrants in the Netherlands used different acculturation strategies depending upon their public versus private life (Arends-Tóth \& Van de Vijver, 2004). Although past PSA research suggests that integration may be the best approach, this strategy may only be viable in a multicultural society (Berry, 2001). In the Netherlands, Turkish immigrants' self-reported behaviors suggesting integration was very different from actual behaviors due to the inability to actuate because of the dominant Dutch culture (Arends-Tóth, Van de Vijver, \& Poortinga, 2006).

There is a wide spectrum of countries' cultures; from those countries that are very multicultural with many differing subcultures without a single dominant culture (ex. Canada, USA, etc.) to those countries where a single dominant culture is maintained (i.e. the Netherlands, Japan, etc.). A country that is multicultural illustrates that cultural minorities are encouraged and positively accommodated (Downie, Koestner, ElGeledi, \& Cree, 2004) and now, due to globalization, many individuals are multicultural. An immigrant who is multi-cultural (or bi-cultural) can identify with the distinct cultures, internalize the cultural schemata and are knowledgeable about the cultural values, norms and beliefs (Brannen \& Thomas, 2010). Due to these factors it is argued that the present standard PSA acculturation framework is unsuitable for global application (Doucerain, Dere, \& Ryder, 2013) and a more multi-dimensional (including individual characteristics, family situation, country multiculturalism, globalization of norms, etc.) version of acculturation is required to accommodate actuality (Downie et al., 2004). The IB research also continues to argue often models are too simplistic to account for individual differences as people may have multiple cultural identities (Arnett, 2002; Leung, Bhagat, Buchan, Erez, \& Gibson, 2005) and "bi-culturals" are a growing demographic group of expatriates (Lakshman, 2013). Our research assists in identifying the commonalities within each field to draw upon and to assist in the development of more complicated models.

The IB field has been researching the importance of cultural adjustment as more employees are being sent overseas on foreign assignments than ever before (Okpara \& Kabongo, 2011) and that it is estimated that as many as $40 \%$ return prematurely due to the inability to adapt to the host countries' culture (Kim \& Slocum, 2008; Tung, 1988). The term used in the IB research is cross-cultural adjustment as well as acculturation, with the IB definition of; the process of adaptation to living and working in a foreign environment with the perceived degree of psychological comfort and familiarity with the new culture (Black, Mendenhall, \& Oddou, 1991). The key difference in the two literature streams (PSA versus IB) is the focus on the work environment in the IB stream, but that is now changing (e.g. Lu et al., 2012).

Another key difference in the two literature streams is that migration could be considered a permanent move by an immigrant, yet in the IB literature the move by an employee could be temporary, lasting between 2 and 5 years. However, due to this short length of time, one could argue that the cultural adjustment process is more important due to the inherent nature of the shortness of time for success. For example, the employees that are sent to overseas assignments are called expatriates and plan to return to their home country at some point (McGinley, 2008). Empirical evidence suggests that cultural adjustment is an important aspect for success in expatriate job performance (Forster, 1997; Harvey, 1996) as the lack of assignee adjustment causes inadequate performance, psychological stress, negative effects on the expatriates' families, as well as the long-term career repercussions upon repatriation of a failed expatriate assignments (Selmer, 2001).

A recent trend in the IB expatriate research examines whether an expatriate's capability to effectively adjust to an international assignment is in fact partly a function of the cultural distance between the expatriate's home country and the host country (Colakoglu \& Caligiuri, 2008). This research mirrors the PSA research in regard to cultural fit. For example, immigrants' personality traits and adaptation to the host country is partly moderated by the degree the personality traits match the norms, values and practices of the host country population (Ward, Leong, \& Low, 2004). 
Other recent PSA research is exploring cultural fit and the use of the standard acculturation framework (Schiefer et al., 2012).

The IB research suggests there are 3 facets of expatriate adjustment of which two are non-work related: interaction with members of the local community and adjustment to the life conditions of the host country (Black, 1988) with the work adjustment the third key factor for success. It has been suggested that there is a lack in the PSA acculturation research combining both the non-work related issues associated with immigration and subsequent overall productivity in employment. This same PSA research focuses on immigration strategies and job-related outcomes such as employee performance, job satisfaction, commitment, interpersonal communication and level conflict (Lu, Samaratunge, \& Härtel, 2011).

Per our review of the separate and distinct research streams, our results identified many common themes and constructs that current research suggests cross-roads the two research streams. Both research streams suggest that acculturation/adjustment will be necessary for the overseas assignee and the immigrant, yet various methods and frameworks have been developed separately. For example, the standard PSA framework of Assimilation, Integration, Marginalization and Separation is not used in the IB research. The IB research focuses on cultural adjustment for work success on a temporary basis, while the PSA research focuses on how immigrants can and should adapt to a new country on a permanent basis. The expatriate is often sent as an extension of corporate headquarters and to retain the corporate culture, hence the acculturation/adaptation process may not the same for both research streams.

Another common theme of both streams of research is the environmental interaction with the individual's traits; illustrating the importance for success of cultural fit and the differences between the home/host cultures. Our research explores these two streams of research for commonalities, illustrate under-researched areas and then we suggest future research. Hence we provide a map of the intellectual structure of research in this intersection to date by analyzing the content of 389 different articles published in scholarly relevant journals.

The results of our research indicate that: (1) the standard $2 \times 2$ matrix of acculturation is insufficient; (2) most past research focuses on USA to other countries and vice versa, suggesting there is much work left to explore other acculturation dimensions ("there and back again" is not the same globally); (3) as global organizations are dominating the marketplace with many various staffing forms, variables such as corporate culture and management interaction will need to be incorporated; (4) research needs to include dynamics over time as many individuals who have worked outside of their home country often become multi-cultural with a global mindset and the typical acculturation framework is insufficient; (5) past acculturation research focuses on the work or the sociocultural context separately, while both need to be included; (6) and the extended family (parents, relatives, close friends, etc.) need to be considered.

\section{Methods and data collection}

Following the procedure suggested by Tranfield, Denyer, and Smart (2003), we structured the process in three steps: (1) journals and database selection depending upon the topic, (2) search criteria and dictionary of descriptors and (3) the method for analyzing and mapping the intellectual structure of the research. Over the next sections we describe each step.

Reproducibility of results is a critical issue in this type of research as it depends on the decisions the researcher makes. Since our goal was to obtain a picture of how scholars have dealt with the acculturation issue throughout the IB literature, we utilized a correspondence analysis, a quantitative method that will ease the reproducibility of our results in the future. As further explained by Beh (2004), Greenacre (1984) and Akturk, Gun, and Kumuk (2007), the homogeneity analysis, sometimes referred to as correspondence analysis, is suitable for representing graphically the patterns underlying behind a space of observations and categorical variables. In our case, this is formed by articles (observations) and descriptors (variables). Accordingly, we selected the homogeneity analysis of variance by mean of alternating least squares (HOMALS), following other similar reviews in the field of business management, such as Furrer, Thomas, and Goussevskaia (2008) in the strategic management field or Dabic, González-Loureiro, and Furrer (2014) for MNEs' strategies.

\subsection{Database selection for sampling articles}

We selected databases within the wide area of Social Sciences. The search strategy depended on the intersection of acculturation and the different forms of overseas assignments, regardless of the journals' specific field. Overseas assignment is a topic that can be positioned in different subfields such as international human resource management or more generally in the IB field, while acculturation can be found in journals publishing in fields such as psychology and sociology. Therefore, not focusing on a particular journal enabled the possibility to include any possible area provided that the topic was acculturation on overseas assignment.

We controlled for the journal quality of the articles selected by selecting two of the most reputed databases indexing and abstracting top-quality articles in Social Sciences, in search of what Ramos-Rodríguez and Ruíz-Navarro (2004) denominated as knowledge certified by top-reputed scholars in a field. Accordingly, we selected the Social Sciences Citation Index-SSCI from the ISI-Web of Sciences and Scopus. Several academic journals may have been excluded, which may be considered a limitation of this study. However, this selection enables future comparisons of our result. 


\subsection{Search criteria and dictionary of descriptors}

We designed search syntax to find the lexemes of the key words in our intersection of acculturation and the different terms scholars may have used to refer to international assignments. Past research on the latter suggested that a lack of clear definition for some of these terms exists. However, a first search yielded a list of both common and emerging forms. Baruch, Dickmann, Altman, and Bournois (2013) distinguish 20 different terms of international work experiences according to seven dimensions, namely time spent, intensity of international contracts, breadth of interaction, legal context, international work instigator, extent of cultural gap and specific position. Some terminologies irrelevant to IB research were excluded because our research was focused on international business so immigration-related forms, non-business positions and voluntary or self-initiated forms were not included. We then summarized these types in the following 6 categories which include the different stages of the international business cycle: expatriate, inpatriate, flexpatriate, propatriate, glopatriate and repatriate.

The definition of expatriate is still controversial in breadth, perhaps influenced by the pace of the dynamics in the business practices as we have moved toward global competition (Harvey, Speier, \& Novicevic, 2001). We found that some scholars have used this term without proper definition within their article. Traditionally the definition used for "expatriate" is individuals that are highly committed to an international position, who usually conduct few assignments for less than five years and frequently in a single firm (Harvey, Fisher, McPhail, \& Moeller, 2013).

Flexpatriates are expatriates but have a low in their lower commitment to a global career. They are more willing to occupy several short-term international positions (McPhail, Fisher, Harvey, \& Moeller, 2012). This characteristic makes them experience acculturation in a different way as traditional expatriates and they may not experience any acculturation due to the shortness of the time immersed in that culture. Baruch et al. (2013) consider the flexpatriates' cultural gap as less relevant, because deep cultural adaptation is not expected.

The propatriate is a new terminology in regard to expatriates. A propatriate can be defined as a professional of overseas assignments, remaining abroad for more than seven to ten years (Harvey et al., 2013). They become a cultural nomad (McPhail et al., 2012) as the number of international assignments and length increase. Therefore, this form of international assignment focuses on a multicultural individual who develops a global mindset as they become more acculturated in many different cultures. Propatriates hold a "global" culture perspective.

Glopatriate is another emerging term for international assignments. Baruch et al. (2013) refer to this form as globetrotting. Individuals immersed in this type of overseas assignments normally seek high levels of autonomy and responsibility and would frequently remain on overseas assignments indefinitely. They normally hold more than 10 years of global experience and several assignments in different cultural contexts with various employers (McPhail et al., 2012). They have higher probability of de-identification with the home-country culture and the organization itself (Harvey et al., 2013).

Inpatriates are those host country and/or third-country nationals who are transferred into the headquarters of a multinational either on a permanent or a semi-permanent basis (Harvey, 1997). These individuals are not reverse expatriates, but brought to corporate headquarters to globalize top management and to develop a global mindset for the firm. They will experience culture shock along with their family and will have corporate culture issues as well (Moeller, Harvey, \& Williams, 2010).

Finally, our research includes the research stream in regard to repatriation. The repatriate closes the cycle of the different forms of international assignments as they return to the home country after one or multiple assignments. An individual who has lived overseas and is returning to their original home country is of particular interest for the study of acculturation since it may imply a reversed form of acculturation or re-acculturation (Linehan \& Scullion, 2002), while Szkudlarek (2010) emphasizing the need for more research on the re-entry issue. Harvey and Novicevic (2006) define the repatriate as the return of global expatriate managers after a sequence of multiple overseas relocations, for extended time periods (e.g. up to 20 years) and/or multiple assignments in a global network organization. The repatriate is often ignored in other literature (Baruch et al., 2013), but is important as the individual has been acculturated overseas and must do so again when returning to their home country. Research suggests that culture shock of returning home often causes these individuals to seek assignments back overseas.

We combined the 6 categories of IB assignment with that of acculturation, following Berry's original work (Berry, 2005; Berry, Kim, Minde, \& Mok, 1987; Berry, Kim, Power, Young, \& Bujaki, 1989) along with the Ward and Kus' (2012) conceptualization and classification scheme. We included the lexeme "accultur*" in order to find all the derivatives. So our search strategy comprised any of the forms of overseas assignments and any of the expressions related with acculturation.

Data were extracted and the search strategy yielded a sample of 389 articles. The main key words were extracted within the title and authors' keywords fields by means of Wordstat 6.1 software. This first step provided a huge list of 990 key words (nouns, adjectives and verbs). The aim of this step was to obtain a workable list of descriptors to be depicted in the map. After deleting some meaningless words for our topic, we adopted a process-based view and summarized those key words in five blocks of information and 34 descriptors: antecedents, moderator or mediating variables; tools and orientations for managing acculturation; outcomes of the process; forms of overseas assignments; and geographical areas. Table 1

illustrates the specific key words within each block and descriptor. The extraction of the specific geographic areas will enable detecting possible gaps regarding contextual particularities. We should mention that the list of this intersection's descriptors emerged naturally from the sample instead of biased inclusions forced by scholars when conducting aprioristic literature reviews. 
Table 1

Dictionary of descriptors and keywords. Descriptors arisen from the review of 389 articles on "acculturation" and forms of overseas assignments (e.g. expatriates, glopatriates, flexpatriates, ...).

\begin{tabular}{|c|c|}
\hline \multicolumn{2}{|c|}{ Antecedents, moderator or mediating variables } \\
\hline Descriptor (short name) & Keywords (content) \\
\hline 1. Context & $\begin{array}{l}\text { Contextual factors; socio-cultural; economic; historical; political; host country; home country; national culture; } \\
\text { cultural distance; cultural tolerance; globaliz(s)ation; economic development; similarity of social institutions; } \\
\text { similarity of language; cultural taboos. }\end{array}$ \\
\hline 2. Organization & $\begin{array}{l}\text { Strategy; firm culture; organizational culture; parent organization; headquarter(s); host organization; host } \\
\text { enterprise; subsidiary/ies; MNC structure; strategic planning; organiz(s)ational support; organiz(s)ational assistance; } \\
\text { succession planning; organiz(s)ational (dynamic) competencies; staffing; recruitment; repatriation program. }\end{array}$ \\
\hline 3. Individual & $\begin{array}{l}\text { Personality traits; extroversion; agreeableness; conscientio(us)sness; neuroticism; openness to experience; technical } \\
\text { competence; behavior(u)r; skill; ability/ies; feeling(s); individual competencies; talent; entrepreneurial orientation; } \\
\text { lived experience; motivation; individual tolerance; managerial resourcefulness; managerial competence; technical } \\
\text { competence; cross-cultural experience; relational skills; individual life cycle; intercultural experience; marital status; } \\
\text { relocation experience; personality type; cultural toughness; culturally tough; self-oriented; others-oriented; } \\
\text { perception; mental health; mood; emotion; sensitivity; cultural adaptability. }\end{array}$ \\
\hline 4. Global mindset & $\begin{array}{l}\text { Global mind(-)set; cultural intelligence; cognitive intelligence; motivational intelligence; metacognitive intelligence; } \\
\text { global business orientation; open-minded; psychological capital; cosmopolitanism; thinking globally; openness to } \\
\text { cultural diversity; global state of mind; propensity to engage; ability to adapt; curiosity; seeking opportunities; glocal. }\end{array}$ \\
\hline 5. Position & $\begin{array}{l}\text { Hierarchical level; job characteristics; role conflict; position in organiz(s)ation; character of the position; focus of } \\
\text { position; manager. }\end{array}$ \\
\hline 6. Commitment & Commitment to the organization; commitment to assignment. \\
\hline 7. Time & $\begin{array}{l}\text { Time of stay; length of stay; temporary; semi-permanent basis; permanent basis; short term; long term; overseas } \\
\text { experience; past experience; previous experience; international experience; extended time period; endurance. }\end{array}$ \\
\hline 8. Diversity & $\begin{array}{l}\text { Diversity workforce; multiculturalism; multicultural workforce; cultural autonomy; third culture; hyper-diversity; } \\
\text { super-diversity; intercultural; cosmopolitan. }\end{array}$ \\
\hline 9. Family & $\begin{array}{l}\text { Family acculturation; family adjustment; adolescent; teen; teenager; children; espouse; husband; Family context; } \\
\text { dual career issues. }\end{array}$ \\
\hline
\end{tabular}

10. Ethnic relations Ethnic stereotypes; ethnic attitudes; ethnic prejudice; multicultural ideology; security; discrimination.

Outcomes

\begin{tabular}{ll}
\hline Descriptor (short name) & Keywords (content) \\
\hline 11. Acculturation & $\begin{array}{l}\text { Acculturation; acculturation process; acculturative; mutual accommodation; psychological adjustment(s); } \\
\text { psychological adaptation(s); sociocultural adjustment(s); sociocultural adaptation(s); contact participation; cultural } \\
\text { adaptation; cultural maintenance; behavior(u)ral shift(s); cultural identity; re-acculturation; cultural } \\
\text { maintenance-contact; cultural maintenance-adoption; exposure to cultural norms. }\end{array}$ \\
& $\begin{array}{l}\text { Cross-cultural adjustment; work adjustment; adjustment to work; cross-cultural management; adjustment to } \\
\text { interacting; adjustment to the general environment; tolerance. }\end{array}$ \\
12. Adjustment & $\begin{array}{l}\text { Harmony; effectiveness; success; life satisfaction; social success; distressing; satisfaction. } \\
\text { 13. Positive outcomes }\end{array}$ \\
14. Negative outcomes & $\begin{array}{l}\text { Stress; acculturative stress; failure; premature termination; life dissatisfaction; social dysfunction; conflict; tension; } \\
\text { anxiety; depressed; depression. }\end{array}$
\end{tabular}

Tools and orientations for managing acculturation

\begin{tabular}{ll}
\hline Descriptor (short name) & Keywords (content) \\
\hline 15. Assimilation & Assimilation; melting pot. \\
16. Separation & Separation, segregation. \\
17. Integration & Integration; biculturalism. \\
18. Marginalization & Marginalization; deculturation; culturelessness; exclusion. \\
19. Socialization & Socialization; social support; social activity; shopping; social networking. \\
20. Coping strategies & Acculturative learning; mentoring; pre(-)departure selection; pre(-)departure training; emotion-focused coping \\
& strategies; problem-focused coping strategies; withdrawal; palliative coping; becoming socially integrated; \\
& avoidance; cognitive avoidance; problem reappraisal; situation control; ethnocentrism; positive comparison; \\
& resignation; negative comparison; seeking task help; expectation change; relationship building; empathizing; culture \\
& learning; planful problem solving; refusing responsibility; confrontation; self-control; giving task help; reinforcement \\
& substitution; micro(-)politics; focusation; seeking emotional support; giving emotional support; cultural change; \\
& development program; pre(-)departure training; organizational support; cross-cultural training. \\
21. Appraisal & Appraisal; assessment; performance; monitoring process; remedial action program; feedback. \\
22. Compensation & Compensation; reward; economically fair; global stock options; salary; international compensation.
\end{tabular}

Forms of overseas assignments

\begin{tabular}{ll}
\hline Descriptor (short name) & Keywords (content) \\
\hline 23. Expatriate & Expatriate. \\
24. Glopatriate & Glopatriate; cultural nomad; global career. \\
25. Flexpatriate & Flexpatriate. \\
26. Inpatriate & Inpatriate; impatriate; patriate; inpatriation; impatriation; patriation. \\
27. Repatriate & Repatriate; repatriation.
\end{tabular}


Table 1 (Continued)

Geographical areas

\begin{tabular}{ll}
\hline Descriptor (short name) & Keywords (content) \\
\hline 28. Europe & EU/Europe/European; North-European; Czech; Finland; Germany/German; Dutch; Greece; Poland; \\
& Russia/Russian/Soviet; Spain; UK/England/British. \\
29. North America & Canada/Canadian; The USA/United-States/United States/USA/California. \\
30. Latin America and the Caribbean & Brazil; Mexico/Mexican. \\
31. Asia-Pacific & Australia/Australian; Japan/Japanese; Korea; New Zealand. \\
32. South-East Asia & Asia/Asian; China/Chinese; Hong-Kong; India; Malaysia; Singapore/Singaporean; Taiwan/Taiwanese; Viet \\
& Nam/Viet Namese. \\
33. Middle East (West Asia) & Arab/Arabia Saudi; Israel; Jordan; Kazakhstan; Kuwait. \\
34. Africa & Africa/African; Afghan/Afghanistan; Algeria/Algerian; Egypt; Nigeria; South-Africa; Sudan; Syria/Syrian. \\
\hline
\end{tabular}

Source: own draft from content analysis of the sample of 389 articles.

\subsection{Method for analyzing and mapping the intellectual structure of research}

Literature review research within the field of international human resource management is conducted by manually reviewing certain articles depending on the scholar's insights and expertise, to demonstrate the validity of the researcher's position, such as Bonache, Brewster, and Suutari (2001), Schuler, Budhwar, and Florkowski (2002) or De Cieri, Cox, and Fenwick (2007). This is appropriate for developing a theoretical or conceptual paper. However, when the intention is to provide the intellectual structure of research of a field, the use of unbiased quantitative methods, at least in part of the process, are advisable. Using a quantitative technique is beneficial to minimize the possible impact of the researcher's bias when conducting the review. In addition, the result based on quantitative techniques enables analyzing a larger sample of articles than when conducted manually.

The HOMALS process is a modernized version of the Guttman's iterative algorithm (1941) and, following the explanation of Hildebrand and Müller-Funk (2012), it aims at minimizing a loss function.

The main outcome of this procedure is shown in a proximity map where the keywords are depicted in two axes. The positions represent an actual distance between the pairs of keywords in terms of association. Those pairs of keywords appearing jointly in large portion of articles will appear closer in the map (Hoffman \& Franke, 1986; Michailidis \& De Leeuw, 1998). Similarly, if they were covered by separate articles in a large extent, they will appear distant. This map enables the detection of possible gaps of research: those descriptors appearing more distant in the map.

In terms of goodness-of-fit indexes it can be analyzed essentially the eigenvalues since this algorithm is finally reduced to a problem of eigenvalues (Michailidis \& De Leeuw, 1998). According to the latter authors, some interesting properties of the HOMALS solution relate with the eigenvalues and the dimensions obtained: (a) the dimensions are nested, i.e. the first $p_{i}$-dimensions are identical when one computes $i+n$ additional dimensions; (b) the solutions for subsequent dimensions are ordered, i.e. the first dimension has the absolute maximum eigenvalue, the second dimension has the maximum absolute eigenvalue subject to the constraint that $X(\cdot, 2)$ is uncorrelated to $X(1, \cdot)$ and so forth; (c) the solution is invariant under rotations of the object scores in the $p$-dimensional space and of the category quantifications.

Therefore, this is an iterative process that helps control the researcher bias when mapping a research field. However, this characteristic must be used carefully in terms of logical meaning in subsequent maps. We strongly recommend a number of points between 25 and 40 depending upon the field studied. This is because less frequent descriptors tend to locate in the edges of the axes while those appearing more frequently tend to locate in the center of the axes. Therefore, we suggest including those descriptors that are less frequent in the period analyzed but that are emerging topics in the recent periods. A limitation of our method is that those topics absolutely eluded by scholars will remain unveiled in the map. Suggesting additional topics is up to the researcher if and only if their relevance is strongly argued in terms of scholarly relevance and utility for practitioners in the field.

\subsection{Descriptors and trends}

Our search strategy yielded 389 articles dealing with acculturation in the IB research. This is consistent with the Dabic, González-Loureiro, and Harvey's (2015) review of the expatriate topic, who found 438 papers, which implies that acculturation is a pervading issue within the topic of international human resource management and yet we lack a comprehensive list of possible frameworks to be applied in this research. We split the time frame of our analysis in two in order to control for the influence of the Berry's two-by-two 'acculturation strategies' matrix (2005). As a result, Tables 2 and 3 shows the breakdown of the frequency of 34 descriptors relative to the total number of articles in each time frame, namely 113 articles during 1976-2004 and 276 papers during 2005-2014.

In terms of frequency, the top keywords addressed in the two literature streams are; organization, context, negative outcomes, adjustment and individual (see Table 2). These terms are often used together as they are related, for example individual and adjustment (or lack there-of) could have negative outcomes. The context of the assignment for the individual also would be combined for research. The organization keyword has gone from 50 mentions in the 28 years of research between 1976 and 2004 to 151 mentions in the 9 years of recent research between 2005 and 2014. As global organizations 
Table 2

Largest past research focus $\left({ }^{*}\right)$.

\begin{tabular}{|c|c|c|c|c|c|c|}
\hline \multirow[t]{2}{*}{ Descriptors } & \multicolumn{2}{|c|}{ P1: 1976-2004 } & \multicolumn{2}{|c|}{ P2: 2005-2014 } & \multirow[t]{2}{*}{ Total } & \multirow[t]{2}{*}{$\%$ to total } \\
\hline & $\overline{\#}$ & $\%$ to total & $\overline{\#}$ & $\%$ to total & & \\
\hline Organization & 50 & $7.01 \%$ & 151 & $8.42 \%$ & 201 & $8.02 \%$ \\
\hline Context & 42 & $5.89 \%$ & 144 & $8.03 \%$ & 186 & $7.42 \%$ \\
\hline Negative outcomes & 56 & $7.85 \%$ & 144 & $8.03 \%$ & 200 & $7.98 \%$ \\
\hline Adjustment & 31 & $4.35 \%$ & 142 & $7.92 \%$ & 173 & $6.90 \%$ \\
\hline Individual & 52 & $7.29 \%$ & 128 & $7.13 \%$ & 180 & $7.18 \%$ \\
\hline Inpatriate & 67 & $9.40 \%$ & 127 & $7.08 \%$ & 194 & $7.74 \%$ \\
\hline Position & 40 & $5.61 \%$ & 110 & $6.13 \%$ & 150 & $5.98 \%$ \\
\hline Expatriate & 57 & $7.99 \%$ & 108 & $6.02 \%$ & 165 & $6.58 \%$ \\
\hline Acculturation & 64 & $8.98 \%$ & 99 & $5.52 \%$ & 163 & $6.50 \%$ \\
\hline South East Asia & 18 & $2.52 \%$ & 82 & $4.57 \%$ & 100 & $3.99 \%$ \\
\hline Appraisal & 29 & $4.07 \%$ & 78 & $4.35 \%$ & 107 & $4.27 \%$ \\
\hline Positive outcomes & 41 & $5.75 \%$ & 73 & $4.07 \%$ & 114 & $4.55 \%$ \\
\hline Asia Pacific & 18 & $2.52 \%$ & 44 & $2.45 \%$ & 62 & $2.47 \%$ \\
\hline Glopatriate & 15 & $2.10 \%$ & 43 & $2.40 \%$ & 58 & $2.31 \%$ \\
\hline North America & 20 & $2.81 \%$ & 39 & $2.17 \%$ & 59 & $2.35 \%$ \\
\hline Coping_strategies & 11 & $1.54 \%$ & 37 & $2.06 \%$ & 48 & $1.91 \%$ \\
\hline Diversity & 11 & $1.54 \%$ & 36 & $2.01 \%$ & 47 & $1.87 \%$ \\
\hline Integration & 9 & $1.26 \%$ & 23 & $1.28 \%$ & 32 & $1.28 \%$ \\
\hline Repatriate & 11 & $1.54 \%$ & 19 & $1.06 \%$ & 30 & $1.20 \%$ \\
\hline Middle East (West Asia) & 6 & $0.84 \%$ & 18 & $1.00 \%$ & 24 & $0.96 \%$ \\
\hline Family & 10 & $1.40 \%$ & 17 & $0.95 \%$ & 27 & $1.08 \%$ \\
\hline Socialization & 11 & $1.54 \%$ & 17 & $0.95 \%$ & 28 & $1.12 \%$ \\
\hline Ethnic relations & 12 & $1.68 \%$ & 17 & $0.95 \%$ & 29 & $1.16 \%$ \\
\hline Global mindset & 2 & $0.28 \%$ & 16 & $0.89 \%$ & 18 & $0.72 \%$ \\
\hline Time & 6 & $0.84 \%$ & 16 & $0.89 \%$ & 22 & $0.88 \%$ \\
\hline Latin America and the Caribbean & 4 & $0.56 \%$ & 12 & $0.67 \%$ & 16 & $0.64 \%$ \\
\hline Europe & 1 & $0.14 \%$ & 11 & $0.61 \%$ & 12 & $0.48 \%$ \\
\hline Africa & 3 & $0.42 \%$ & 11 & $0.61 \%$ & 14 & $0.56 \%$ \\
\hline Commitment & 4 & $0.56 \%$ & 9 & $0.50 \%$ & 13 & $0.52 \%$ \\
\hline Flexpatriate & 6 & $0.84 \%$ & 8 & $0.45 \%$ & 14 & $0.56 \%$ \\
\hline Compensation & 3 & $0.42 \%$ & 7 & $0.39 \%$ & 10 & $0.40 \%$ \\
\hline Assimilation & 2 & $0.28 \%$ & 5 & $0.28 \%$ & 7 & $0.28 \%$ \\
\hline Marginalization & 0 & $0.00 \%$ & 2 & $0.11 \%$ & 2 & $0.08 \%$ \\
\hline Separation & 1 & $0.14 \%$ & 1 & $0.06 \%$ & 2 & $0.08 \%$ \\
\hline Total freq. & 713 & $100.00 \%$ & 1794 & $100.00 \%$ & 2507 & $100.00 \%$ \\
\hline
\end{tabular}

(*) Sorted by the most recent period (2005-2014).

continue to dominate the business landscape, the focus will become more upon MNCs, their corporate culture and the management of global employees.

In terms of trends occurring in the research (see Table 3), keywords such as adjustment, Southeast Asia, context and organization continue to be researched. However nascent research that appears to be of new interest is Europe, global mindset, Africa, the Middle East, Latin America and the Caribbean and coping strategies. Past research focused on western countries (in particular, USA) adapting to foreign markets or migrants adapting to the USA. Now research in the global marketplace is exploring regions that have been largely ignored, but are becoming more prominent in the global economy.

\subsection{The map of the intellectual structure of research on acculturation in IB research}

The HOMALS procedure conducted on the matrix of 389 articles by 34 descriptors delivered the map of the intellectual structure of research on acculturation in international assignments (see Fig. 1). The map should be interpreted along with the frequencies showed in Table 1.

Following the suggestion of Hoffman and Franke (1986), Hoffman and De Leeuw (1992) and Michailidis and De Leeuw, once the map is obtained, one must label the poles according to the descriptors located proximal to each pole. The HOMALS procedure yields the quantifications, i.e. the coordinates of each descriptor in the two dimensions.

On the right side, descriptors are governed by glopatriate, time and repatriate in frequency terms. If we included lower frequent terms with high values and proximal descriptors, then flexpatriate, Europe, compensation and family are included. This pole seems to summarize the role of time on the acculturation process, in particular in three relevant forms of international assignments: glopatriates, repatriates and flexpatriates. This is why we suggest labeling this pole as "dynamics over time".

On the left side, descriptors relate mainly with marginalization, integration and assimilation hold the highest values in absolute terms in this pole. Global mindset, adjustment and diversity locate near. This pole appears to recompile the traditional acculturation strategies along with an emerging issue: the need for global mindset. If we include Africa as the geographic area 
Table 3

Trends in research $(*)$.

\begin{tabular}{|c|c|c|c|}
\hline Descriptors & \% to total in P1 (1976-2004) & \% to total in P2 (2005-2014) & Change from $\mathrm{P} 1$ to $\mathrm{P} 2$ \\
\hline Europe & $0.14 \%$ & $0.61 \%$ & $90.91 \%$ \\
\hline Global mindset & $0.28 \%$ & $0.89 \%$ & $87.50 \%$ \\
\hline Adjustment & $4.35 \%$ & $7.92 \%$ & $78.17 \%$ \\
\hline South East Asia & $2.52 \%$ & $4.57 \%$ & $78.05 \%$ \\
\hline Africa & $0.42 \%$ & $0.61 \%$ & $72.73 \%$ \\
\hline Context & $5.89 \%$ & $8.03 \%$ & $70.83 \%$ \\
\hline Coping_strategies & $1.54 \%$ & $2.06 \%$ & $70.27 \%$ \\
\hline Diversity & $1.54 \%$ & $2.01 \%$ & $69.44 \%$ \\
\hline Organization & $7.01 \%$ & $8.42 \%$ & $66.89 \%$ \\
\hline Middle East (West Asia) & $0.84 \%$ & $1.00 \%$ & $66.67 \%$ \\
\hline Latin America and the Caribbean & $0.56 \%$ & $0.67 \%$ & $66.67 \%$ \\
\hline Glopatriate & $2.10 \%$ & $2.40 \%$ & $65.12 \%$ \\
\hline Position & $5.61 \%$ & $6.13 \%$ & $63.64 \%$ \\
\hline Appraisal & $4.07 \%$ & $4.35 \%$ & $62.82 \%$ \\
\hline Time & $0.84 \%$ & $0.89 \%$ & $62.50 \%$ \\
\hline Negative outcomes & $7.85 \%$ & $8.03 \%$ & $61.11 \%$ \\
\hline Integration & $1.26 \%$ & $1.28 \%$ & $60.87 \%$ \\
\hline Assimilation & $0.28 \%$ & $0.28 \%$ & $60.00 \%$ \\
\hline Individual & $7.29 \%$ & $7.13 \%$ & $59.38 \%$ \\
\hline Asia Pacific & $2.52 \%$ & $2.45 \%$ & $59.09 \%$ \\
\hline Compensation & $0.42 \%$ & $0.39 \%$ & $57.14 \%$ \\
\hline Commitment & $0.56 \%$ & $0.50 \%$ & $55.56 \%$ \\
\hline North America & $2.81 \%$ & $2.17 \%$ & $48.72 \%$ \\
\hline Inpatriate & $9.40 \%$ & $7.08 \%$ & $47.24 \%$ \\
\hline Expatriate & $7.99 \%$ & $6.02 \%$ & $47.22 \%$ \\
\hline Positive outcomes & $5.75 \%$ & $4.07 \%$ & $43.84 \%$ \\
\hline Repatriate & $1.54 \%$ & $1.06 \%$ & $42.11 \%$ \\
\hline Family & $1.40 \%$ & $0.95 \%$ & $41.18 \%$ \\
\hline Acculturation & $8.98 \%$ & $5.52 \%$ & $35.35 \%$ \\
\hline Socialization & $1.54 \%$ & $0.95 \%$ & $35.29 \%$ \\
\hline Ethnic relations & $1.68 \%$ & $0.95 \%$ & $29.41 \%$ \\
\hline Flexpatriate & $0.84 \%$ & $0.45 \%$ & $25.00 \%$ \\
\hline Marginalization & $0.00 \%$ & $0.11 \%$ & $100.00 \%$ \\
\hline Separation & $0.14 \%$ & $0.06 \%$ & $0.00 \%$ \\
\hline Total & $100.00 \%$ & $100.00 \%$ & \\
\hline
\end{tabular}

$\left({ }^{*}\right)$ Sorted by "Per Cent Change" ignoring "Marginalization".

more proximal to this pole, then it becomes apparent that the pole combines new challenges and the traditional acculturation strategies. We then imply labeling this pole as "new applications of acculturation strategies".

In the upper side of the map, descriptors are flexpatriate, adjustment, global mindset, organization, integration and diversity. South East Asia and Africa reached the most extreme values for geographical areas in that pole. The content seems to be related with the actions and process of adaptation at work, at an organizational level. Accordingly, we propose labeling this as "adjustment at work".

On the bottom side, key descriptors are glopatriate, compensation, family, separation, repatriate, assimilation, inpatriate, expatriate and marginalization. Europe is the main geographical area. A joint consideration of the descriptors seems to suggest issues dealing with family issues in accordance with the Berry's acculturation strategies. We then suggest that "family acculturation" appropriately represents the content of this pole.

\section{Discussion of results}

Past research has been governed by adjustment-acculturation as showed in the poles of the second dimension. Two complementary viewpoints that suggest the existence of two levels of analysis: the role of work and the wider scope of the place where he/she and his/her family live. Also, extant research on acculturation strategies has frequently neglected the issue of dynamics along time, as the first dimension showed.

The adjustment-acculturation has been researched as mutually exclusionary realms and scholars have devoted little effort to join the analyses. In spite of the Black and colleagues' attempts (e.g. Black et al., 1991) to push forward an integrative viewpoint of domestic and international adjustment or those emphasizing the role of spouses (e.g. Black \& Stephens, 1989), there is still room for wider paradigms by combining tensions emerging at multiple concentric levels around the assignee. Moreover, Black (1988, 1990) and colleagues (Black et al., 1991) grouped issues around adjustment at three levels: adjustment to work, adjustment to interacting with host nationals and adjustment to the general environment. However, little is known about interactive effects of other levels of analysis. 


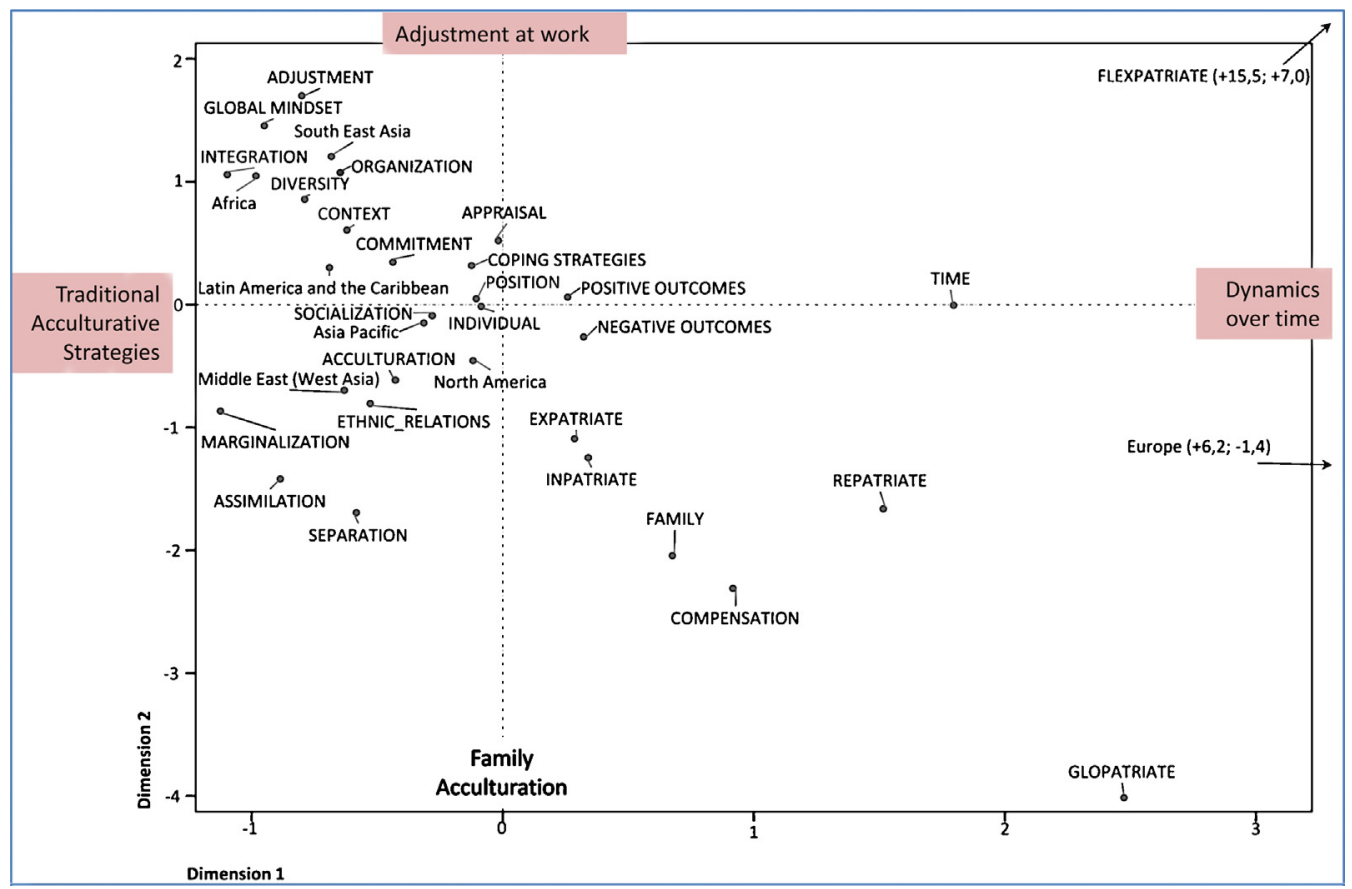

Fig. 1. Map of the intellectual structure of research on acculturation in International Business Research (quantifications of the Homals procedure for the full period 1976-2014)

Source: own draft from the 389 articles.

The interaction individual-organization at both origin and host locations is the first level of analysis. A wider focus will enlarge the scope of analysis toward a second type of organization, i.e. his/her family group, along with all the family's individual living abroad and those remaining at the home country.

Articles dealing with acculturation in international assignees quite often consider work and sociocultural context separately. It is not solely a question of individual adaptation at work or family adaptation in the host country. It is a question of both levels. This implies that more than two cultures (dominant and dominated) may be interacting because of the possibility of small cultural differences in the family group. As globalization continues to "flatten" the world and international assignments become a common practice, it is very likely that we may find an increasing number of multicultural families. This type of family offers an interesting opportunity to research further as well as to assist to build more complete paradigms due to the complexity of this issue.

The possibility of interactive effects between both levels of analysis, work and home at origin and host cultures, should be further incorporated to future frameworks. This view may open new extensions for future research if we include the notion of extended family, i.e. the relationships with parents, relatives and close friends who remained at the origin country. They must go through their own acculturation process when maintaining their relationships with family located overseas. Acculturation spreads the required adaptation from work to personal life, while scholars refer to adjustment as the impact of adaptation at work. As the map shows, there is room for more integrative studies of adjustment and acculturation instead of ascribing the research to one or another.

The horizontal dimension is about the applications of acculturative strategies beyond the cultural differences of Western and Easter perspectives. Locations such as Latin-America and the Caribbean or the big "unknown" Africa deserve further attention from scholars if a universal theory of managing acculturation is to be developed. Furthermore, global business continues to evolve and topics such as international ventures such as the INVs, born-global or the reversed viewpoint of emerging markets multinationals deserve further attention (see for instance Thite, Wilkinson, \& Shah, 2012 or Fan, Zhang, \& Zhu, 2013). Those topics/organizational structures and issues require a more complete framework beyond the simplistic view of two-by-two matrix.

In the horizontal dimension, we found the most under investigated issue within this field, the concept of time with the main descriptors. More empirical research is needed to reach a longitudinal perspective of acculturation, a viewpoint along time that may yield a theory of stages and a life cycle along the lifetime of international assignees and international organizations. To date, time has been considered as part of the definition of flexpatriates. A pervasive issue is the time of assignment. Research on acculturation has yielded an impressive list of coping strategies, as those Stahl and Caligiuri's (2005) documented in their study of coping strategies adopted by expatriates. Coping is defined as the efforts "to manage environmental and internal demands and conflicts among them, which tax or exceed a person's resources" 
(Lazarus \& Launier, 1978, p. 311). Stahl and Caligiuri (2005) applied the latter definition to expatriates, so they define coping strategies as the actions and procedures expatriates use to manage, reduce or overcome the environmental (e.g. cultural differences) and internal demands (e.g. role conflict) they encounter. These authors showed that problem-focused rather than emotion-focused strategies may be more effective regarding the intention to remain on the international assignment. However, the latter is moderated by contextual factors such as hierarchical level, time on the assignment and cultural distance. Accordingly, time should be included as a critical moderator in revisiting some studies on acculturation, while coping strategies open a multidimensional path for future research on acculturation.

However, major difficulties arise when one tries to conduct a quantitative, longitudinal study because of the problems to obtain large and consistent samples required by duration models, such as Cox regressions. Perhaps scholars should conduct their efforts to designing collaborative research projects for the sake of science and practitioners. We still lack studies analyzing the long-term effect of acculturation, perhaps influenced by the relative adolescence of this topic. Over the next decades and after more than 40 years of research on issues such as expatriates (see Dabic et al., 2015), there has been amassed a relevant body of knowledge in international human resource management, in order to build an integrative theory of international assignments.

\section{Conclusions and implications}

Our research attempts to review the appropriateness of extant acculturation frameworks in regard to the differing types of overseas assignments, suggest where acculturation in the 21st century should focus and to propose a future research agenda to guide more scholarly work in this area. The motivation for our research is there are two streams of overlapping literature; that of acculturation and international assignee adjustment. There are similarities and differences between the two literature streams and recent research suggests that they now seem to be coalescing with a focus on both the cultural nuances of moving overseas, adaptation and subsequent job success. In the past, the intercultural research field focused on migrant acculturation and their strategies for adaptation (Assimilation, Integration, Marginalization and Separation) and how variations in acculturation affect how well individuals adapt to their society. IB research primarily used the term crosscultural adjustment and is defined as the process of adaptation to living and working in a foreign environment with the perceived degree of psychological comfort and familiarity with the new culture. The key difference in the two literature streams is the focus on the work environment more so in the IB stream than in the cross-cultural literature, but that appears to be changing.

Recent acculturation research is now examining research that has been the focus of the IB field, that of examining work related attitudes in regard to acculturation orientations and work-related well-being (but the IB field does not use the adaptation framework, but will often resort to Hofstede's framework of national culture amongst others). In the intercultural field researchers argue that there is a lack in the acculturation research combining both the non-work related issues associated with immigration and subsequent overall productivity in employment. As such, new research is introducing a research focus on immigration strategies and job-related outcomes such as employee performance, job satisfaction, commitment, interpersonal communication and level conflict.

A recent trend in expatriate research examines whether an expatriate's capability to effectively adjust to an international assignment is in fact partly a function of the cultural distance between the expatriate's home country and the host country. This research mirrors the intercultural research in regard to cultural fit. For example, immigrants' personality traits and adaptation to the host country is partly moderated by the degree the personality traits match the norms, values and practices of the host country population.

Our research attempts to identify some of the overlaps, under researched areas and suggestions for future research. Both global mindset and time are key concepts in relation to acculturation either separately or as joint variables. Although successful corporations have identified the family importance in the success of overseas assignments due to their intense training of both the expatriate and their family, our research suggests that there is still work to do in this area since scholars in this topic have generally focused on willingness to take an assignment and adjustment. Other important topics, such as the careers of 'trailing partners' and the difficulties of fulfilling extended family obligations (e.g., elder care) while geographically dispersed have been less well researched. Relative to expatriate families, little is known about the family experiences of other practices of global employees such as frequent international business travelers (IBTs) or short-term assignees global domestics. Finally, although there is significant comparisons of East versus West (China and USA for example), there is a dearth of research in both Europe and Africa. Both areas are of interest in regard to acculturation as Africa is a difficult research area with one billion people that are vastly different over a huge diverse set of cultures, while Europe is a mature stable marketplace with dominant cultures that are united mostly under one currency.

Our research has some implications for practitioners. Currently, there is no universal theory for guidance and results will depend on the context of the situation. In the case of acculturation this context is multifaceted so it is even more complicated. Therefore, what is a best practice in the USA may not be valid in another country. Practitioners should take into account the context(s) where their "best practices" worked and then compare it/them with the new context in order to make the adaptations required. The success of the process of adjustment at work does not depend solely on what occurs in the workplace, but must include a wider perspective: that of the family acculturation process. The type of overseas assignment and the cultural difference between home and host countries are determinant factors for the organization to adopt certain 
“best practices". This entails that the compensation is not only for the expatriate but must include the other family members' needs as part of the compensation.

\section{References}

Akturk, D., Gun, S., \& Kumuk, T. (2007). Multiple correspondence analysis technique used in analyzing the categorical data in social sciences. Journal of Applied Sciences, 7(4), 585-588.

Arends-Tóth, J., \& Van de Vijver, F. J. (2004). Domains and dimensions in acculturation: Implicit theories of Turkish-Dutch. International Journal of Intercultural Relations, 28(1), 19-35.

Arends-Tóth, J., Van de Vijver, F. J., \& Poortinga, Y. H. (2006). The influence of method factors on the relation between attitudes and self-reported behaviors in the assessment of acculturation. European Journal of Psychological Assessment, 22(1), 4-12.

Arnett, J. J. (2002). The psychology of globalization. American Psychologist, 57(10), 774.

Baruch, Y., Dickmann, M., Altman, Y., \& Bournois, F. (2013). Exploring international work: Types and dimensions of global careers. The International Journal of Human Resource Management, 24(12), 2369-2393.

Beh, E. J. (2004). Simple correspondence analysis: A bibliographic review. International Statistical Review, 72(2), 257-284

Berry, J. W. (1997). Immigration, acculturation, and adaptation. Applied Psychology, 46(1), 5-34.

Berry, J. W. (2001). A psychology of immigration. Journal of Social Issues, 57(3), 615-631.

Berry, J. W. (2005). Acculturation: Living successfully in two cultures. International Journal of Intercultural Relations, 29(6), 697-712.

Berry, J. W., Kim, U., Minde, T., \& Mok, D. (1987). Comparative studies of acculturative stress. International Migration Review, 21(3), 491-511.

Berry, J. W., Kim, U., Power, S., Young, M., \& Bujaki, M. (1989). Acculturation attitudes in plural societies. Applied Psychology, $38(2), 185-206$.

Berry, J. W., Phinney, J. S., Kwak, K., \& Sam, D. L. (2006). Introduction: Goals and research framework for studying immigrant youth.

Berry, J. W., \& Sabatier, C. (2010). Acculturation, discrimination, and adaptation among second generation immigrant youth in Montreal and Paris. International Journal of Intercultural Relations, 34(3), 191-207.

Black, J. S. (1988). Work role transitions: A study of American expatriate managers in Japan. Journal of International Business Studies, 19(2), 277-294.

Black, J. S. (1990). The relationship of personal characteristics with the adjustment of Japanese expatriate managers. Management International Review, 30(2), 119-134.

Black, J. S., Mendenhall, M., \& Oddou, G. (1991). Toward a comprehensive model of international adjustment: An integration of multiple theoretical perspectives. Academy of Management Review, 16(2), 291-317.

Black, J. S., \& Stephens, G. K. (1989). The influence of the spouse on American expatriate adjustment and intent to stay in Pacific Rim overseas assignments. Journal of Management, 15(4), 529-544

Bonache, J., Brewster, C., \& Suutari, V. (2001). Expatriation: A developing research agenda. Thunderbird International Business Review, 43(1), 3-20.

Brannen, M. Y., \& Thomas, D. C. (2010). Bicultural individuals in organizations implications and opportunity. International Journal of Cross Cultural Management, 10(1), 5-16.

Colakoglu, S., \& Caligiuri, P. (2008). Cultural distance, expatriate staffing and subsidiary performance: The case of US subsidiaries of multinational corporations. The International Journal of Human Resource Management, 19(2), 223-239.

Dabic, M., González-Loureiro, M., \& Furrer, O. (2014). Research on the strategy of multinational enterprises: Key approaches and new avenues. BQR BusinesS Quarterly Research, 17(2), 129-148.

Dabic, M., González-Loureiro, M., \& Harvey, M. (2015). Evolving research on expatriates: What is ‘known’ after four decades (1970-2012). The International Journal of Human Resource Management, 26(3), 316-337.

De Cieri, H., Cox, J. W., \& Fenwick, M. (2007). A review of international human resource management: Integration, interrogation, imitation. International Journal of Management Reviews, 9(4), 281-302.

Doucerain, M., Dere, J., \& Ryder, A. G. (2013). Travels in hyper-diversity: Multiculturalism and the contextual assessment of acculturation. International Journal of Intercultural Relations, 37(6), 686-699.

Downie, M., Koestner, R., ElGeledi, S., \& Cree, K. (2004). The impact of cultural internalization and integration on well-being among tricultural individuals. Personality and Social Psychology Bulletin, 30(3), 305-314.

Fan, D., Zhang, M. M., \& Zhu, C. J. (2013). International human resource management strategies of Chinese multinationals operating abroad. Asia Pacific Business Review, 19(4), 526-541.

Forster, N. (1997). The persistent myth of high expatriate failure rates: A reappraisal. International Journal of Human Resource Management, 8(4), 414-433.

Furrer, O., Thomas, H., \& Goussevskaia, A. (2008). The structure and evolution of the strategic management field: A content analysis of 26 years of strategic management research. International Journal of Management Reviews, 10(1), 1-23.

Greenacre, M. J. (1984). Theory and application of correspondence analysis. London: Academic Press.

Guttman, L. (1941). The quantification of a class of attributes: A theory and method of scale construction. In P. Horst (Ed.), The prediction of personal adjustment (pp. 319-348). New York: Social Science Research Council.

Harvey, M. (1996). The selection of managers for foreign assignments: A planning perspective. The Columbia Journal of World Business, 31 (4), 102-118.

Harvey, M. (1997). Inpatriation training: The next challenge for international human resource management. International Journal of Intercultural Relations, 21(3), 393-428.

Harvey, M., Fisher, R., McPhail, R., \& Moeller, M. (2013). Aligning global organizations' human capital needs and global supply-chain strategies. Asia-Pacific Journal of Human Resources, 51(1), 4-21.

Harvey, M., \& Novicevic, M. N. (2006). Development of an efficient architecture for the inpatriation of managers. In M. J. Morley, N. Heraty, \& D. G. Collings (Eds.), International human resource management and international assignments. Basingstoke: Palgrave.

Harvey, M., Speier, C., \& Novicevic, M. (2001). A theory-based framework for strategic global human resource staffing policies and practices. International Journal of Human Resource Management, 12(6), 898-915.

Hildebrand, K. F., \& Müller-Funk, U. (2012). Homals for dimension reduction in information retrieval. In W. A. Gaul, A. Geyer-Schulz, L. Schmidt-Thieme, \& J. Kunze (Eds.), Challenges at the interface of data analysis, computer science, and optimization (pp. 353-361). Berlin: Springer Heidelberg.

Hoffman, D. L., \& De Leeuw, J. (1992). Interpreting multiple correspondence analysis as a multidimensional scaling method. Marketing Letters, 3(3), $259-272$.

Hoffman, D. L., \& Franke, G. R. (1986). Correspondence analysis: Graphical representation of categorical data in marketing research. Journal of Marketing Research, 23(3), 213-227.

Juang, L. P., Nguyen, H. H., \& Lin, Y. (2006). The ethnic identity, other-group attitudes, and psychosocial functioning of Asian American emerging adults from two contexts. Journal of Adolescent Research, 21(5), 542-568.

Kim, K., \& Slocum, J. W., Jr. (2008). Individual differences and expatriate assignment effectiveness: The case of US-based Korean expatriates. Journal of World Business, 43(1), 109-126.

Lakshman, C. (2013). Biculturalism and attributional complexity: Cross-cultural leadership effectiveness. Journal of International Business Studies, 44(9), 922-940.

Lazarus, R. S., \& Launier, R. (1978). Stress-related transactions between person and environment. In L. A. Pervin, \& M. Lewis (Eds.), Perspectives in interactional psychology (pp. 287-327). New York: Plenum Press.

Leong, C. H. (2014). Social markers of acculturation: A new research framework on intercultural adaptation. International Journal of Intercultural Relations, $38,120-132$ 
Leung, K., Bhagat, R. S., Buchan, N. R., Erez, M., \& Gibson, C. B. (2005). Culture and international business: Recent advances and their implications for future research. Journal of International Business Studies, 36(4), 357-378.

Linehan, M., \& Scullion, H. (2002). The repatriation of female international managers: An empirical study. International Journal of Manpower, 23(7), 649-658.

Lu, Y., Samaratunge, R., \& Härtel, C. E. (2011). Acculturation strategies among professional Chinese immigrants in the Australian workplace. Asia Pacific Journal of Human Resources, 49(1), 71-87.

Lu, Y., Samaratunge, R., \& Härtel, C. E. (2012). The relationship between acculturation strategy and job satisfaction for professional Chinese immigrants in the Australian workplace. International Journal of Intercultural Relations, 36(5), 669-681.

McGinley, J. (2008). Expatriate adjustment within a social context: Examination of a sample in Russia. Journal of Social, Evolutionary, and Cultural Psychology, 2(2), 56-68.

McPhail, R., Fisher, R., Harvey, M., \& Moeller, M. (2012). Staffing the global organization: “Cultural nomads”. Human Resource Development Quarterly, 23(2), 259-276.

Michailidis, G., \& De Leeuw, J. (1998). The Gifi system of descriptive multivariate analysis. Statistical Science, 13(4), 307-336.

Moeller, M., Harvey, M., \& Williams, W.(2010). Socialization of inpatriate managers to the headquarters of global organizations: A social learning perspective. Human Resource Development Review, 9(2), 169-193.

Navas, M., García, M. C., Sánchez, J., Rojas, A. J., Pumares, P., \& Fernández, J. S. (2005). Relative acculturation extended model (RAEM): New contributions with regard to the study of acculturation. International Journal of Intercultural Relations, 29(1), 21-37.

Okpara, J. O., \& Kabongo, J. D. (2011). Cross-cultural training and expatriate adjustment: A study of western expatriates in Nigeria. Journal of World Business, $46(1), 22-30$

Peeters, M. C., \& Oerlemans, W. G. (2009). The relationship between acculturation orientations and work-related well-being: Differences between ethnic minority and majority employees. International Journal of Stress Management, 16(1), 1-24.

Ramos-Rodríguez, A., \& Ruíz-Navarro, J. (2004). Changes in the intellectual structure of strategic management research: A bibliometric study of the Strategic Management Journal, 1980-2000. Strategic Management Journal, 25(10), 981-1004.

Rudmin, F. (2003). Critical history of the acculturation psychology of assimilation, separation, integration and marginalization. Review of General Psychology, 7(1), 3-37.

Schiefer, D., Möllering, A., \& Daniel, E. (2012). Cultural value fit of immigrant and minority adolescents: The role of acculturation orientations. International Journal of Intercultural Relations, 36(4), 486-497.

Schuler, R. S., Budhwar, P. S., \& Florkowski, G. W. (2002). International human resource management: Review and critique. International Journal of Management Reviews, 4(1), 41-70.

Schwartz, S. J., Unger, J. B., Zamboanga, B. L., \& Szapocznik, J. (2010). Rethinking the concept of acculturation: Implications for theory and research. American Psychologist, 65(4), 237.

Scottham, K. M., \& Dias, R. H. (2010). Acculturative strategies and the psychological adaptation of Brazilian migrants to Japan. Identity: An International Journal of Theory and Research, 10(4), 284-303.

Selmer, J. (2001). Psychological barriers to adjustment and how they affect coping strategies: Western business expatriates in China. International Journal of Human Resource Management, 12(2), 151-165.

Stahl, G. K., \& Caligiuri, P. (2005). The effectiveness of expatriate coping strategies: The moderating role of cultural distance, position level, and time on the international assignment. Journal of Applied Psychology, 90(4), 603-615.

Szkudlarek, B. (2010). Reentry - A review of the literature. International Journal of Intercultural Relations, 34(1), 1-21.

Thite, M., Wilkinson, A., \& Shah, D. (2012). Internationalization and HRM strategies across subsidiaries in multinational corporations from emerging economies - A conceptual framework. Journal of World Business, 47(2), 251-258.

Tranfield, D., Denyer, D., \& Smart, P. (2003). Towards a methodology for developing evidence-informed management knowledge by means of systematic review. British Journal of Management, 14(3), 207-222.

Tung, R. L. (1988). The new expatriates: Managing human resources abroad. Ballinger Publishing Co./Harper \& Row Publishers.

Wang, S. C., Schwartz, S. J., \& Zamboanga, B. L. (2010). Acculturative stress among Cuban American college students: Exploring the mediating pathways between acculturation and psychosocial functioning. Journal of Applied Social Psychology, 40(11), 2862-2887.

Ward, C., \& Kus, L. (2012). Back to and beyond Berry’s basics: The conceptualization, operationalization and classification of acculturation. International Journal of Intercultural Relations, 36(4), 472-485.

Ward, C., Leong, C. H., \& Low, M. (2004). Personality and sojourner adjustment An exploration of the big five and the cultural fit proposition. Journal of Cross-Cultural Psychology, 35(2), 137-151. 